\title{
Practical Research on Application of Traditional Chinese Elements in Graphic Design
}

\author{
Chao Zhan \\ China Academy of Art, Hangzhou, 310024, China
}

\begin{abstract}
Excellent Traditional Chinese cultural elements are precious national treasures of China. They display the long history of Chinese nation for five thousand years to the world. At the same time, these excellent traditional Chinese cultural elements are also served as important "soft strength" of China for the development of opening to the outside world. In the field of graphic design and contemporary art, various new elements emerged. Thus, it is necessary for us to combine traditional Chinese elements with modern thoughts, allow China's graphic design to have more national features and carry forward our local culture and integrate it with the world.
\end{abstract}

Key words: Traditional Chinese elements, graphic design, practical research

With rapid development at present, many new thoughts and new elements are continuously integrated into our life. At the same time, great changes took place in people's world view, value and view of life. We are led to move forward by progress of times. Moreover, huge changes took place in our daily life. Beautiful life is found by eyes. Now, our aesthetic orientation was also changed. As a result, China's graphic design is greatly influenced. Graphic design covers traditional culture treasures of Chinese nation for five thousand years. At the same time, it also displays important sources of intangible heritage of national culture. However, China is now under the background of globalization. We should show traditional culture elements in graphic design. Moreover, we should also make an in-depth research on huge values of our traditional elements, adding new thoughts into traditional elements to result in more brilliant achievements.

\section{Traditional Chinese elements are served as strong foundation that can not be neglected in the development of graphic design.}

Traditional Chinese cultural elements are diversified, which cover humanistic characteristics of China for five thousand years and spiritual connotation of Chinese people. China is a world power, which contains different customs, thoughts and 
religious cultures of different nations. However, a kind of beautify is embodied in all these elements. It is beauty belonged to the whole China. We inject this into graphic design. At present, graphic design full of "Chinese style” is not simply visual national pattern or surface morphology of symbol. More importantly, its creativity allows Chinese cultural elements as media to integrate Chinese elements into new thoughts and make an in-depth research on traditional patterns, symbols and traditional culture, so as to express the pursuit for Chinese style. Just like the case that people loose air, graphic design will loose the foundation for development and progress if it looses traditional Chinese cultural elements. Works without spiritual charm are unworthy of people's appreciation for ever. Therefore, traditional Chinese cultural elements are served the foundation for the development of graphic design.

\section{Traditional Chinese cultural elements applied into contemporary graphic design}

(I) Application of traditional colors

Color of the five elements is a system with great national features in traditional Chinese elements. In ancient times, yin-yang and five elements bore profound influence on the nation. Five colors of black, white, green, red and yellow represent different symbols. As the king of all colors, black is an integral part of Chinese colors. It symbolizes dignity and equanimity. White is served as the color synthesis, which gives people infinite imagination. It is elegant. Green symbolizes purity and hope. Red symbolizes good luck and fortune. Yellow symbolizes glory and wealth. As precious crystal of history, the five colors accompanied the Chinese cultural origin. They display vitality of traditional Chinese elements as well as inheritance for five thousand years. To a large extent, China's five color theory influences people from generation to generation. In daily life and color matching, it brings forth great help. At the same time, it is also of great function in continuous reference and innovation of graphic design.

(II) Application of folk art

Since ancient times, Chinese people love labor and life. From high streets and back lanes, we can feel various forms of art that people love to see and hear, such as paper cutting, types of facial makeup in operas and painting. Upon these traditions, the present folk art is more innovative and colorful. Everyone presumably knows Beijing Olympics held in 2008. The philosophy of folk art was adopted as the 
creative inspiration of the "auspicious cloud" torch. Visually, it gives people great impact force. Moreover, it is also convenient for media transmission.

Types of facial makeup in operas are widely known in China. It is also well known in the world. The song of "Rapper Face" was covered by many foreign friends. China's art of facial makeup is expressed incisively and vividly by this song. In the brand design of "Zhangfei Beef”, the beef is internally red and externally black, extremely like the colors of facial makeup. Therefore, it is packaged by virtue of this image. It is not only unique but also convenient for identification.

(III) Application of traditional calligraphy

It can be said that calligraphy is the essence of Chinese cultural elements. For thousands of years, calligraphic art can not be neglected. At the same time, it is also served as the favorite item of people. Everyone presumably knows the most famous work of the grand calligrapher Wang Xizhi in ancient times - Orchid Pavilion. In this preface, Wang Xizhi’s calligraphic art is expressed fully and delightfully. The same words are certainly different in terms of style of writing. It becomes unique in the history of calligraphy. Wang Xizhi's calligraphic art is praised as "floating as clouds and strong and vigorous as dragon”. If traditional calligraphic art can be perfectly applied into graphic design, it certainly will create the most vivid works. Here, Beijing Olympic Games worthy of being proud by all Chinese people will be mentioned again. The emblem "Chinese Seal • Dancing Beijing” is a successful example which apply traditional calligraphic art into graphic design. It not only presents Olympic Spirits but also shows to the world China's calligraphic culture with a long history.

\section{Traditional Chinese elements should be combined with new thoughts of modern graphic design.}

Among all graphic design works at present, there are two largest issues requiring timely improvement: the first one is to refuse poor thinking. So-called poor thinking refers to indiscriminate imitation of traditional Chinese cultural elements in many graphic designs. Moreover, it is also in a completely westernized state. For this point, we need to make timely adjustment. Or, future graphic design will suffer from great negative influence. We should correctly treat traditional cultural elements and properly combine these elements with new modern thoughts, so as to realize the essence of China's graphic design and meet diversified needs of Chinese society. The second one is that there is generality but no personality. Talking about 
traditional Chinese cultural elements, 99 out of 100 people will think about types of facial makeup in operas, China's symbol - dragon and paper cutting. Most people will think about these elements at once. Moreover, many graphic designers also selected these elements in the first choice. Actually, Chinese elements include more contents. I hope that everyone can extend Chinese culture and view from a more connotative level.

In the final analysis, I want to tell excellent Chinese graphic designers not to be confined to superficial form of design. Real graphic design certainly will be not confined to tradition or nation. We should extract the essence, integrate graphic design with "Chinese style" into new modern elements and show the world the beauty of oriental art.

\section{IV.Conclusion:}

Chinese national culture has a long history. Each period left culture heritage in different styles for us. We are lucky, because we possess treasures prepared by our predecessors since our birth. With rapid development at present, traditional Chinese cultural elements are of great charms for us. In the process of integration between traditional elements and new era elements, we are changing, moving forward and making great efforts. While carrying forward traditional culture, we also enriched the cultural connotation of graphic design in the present world. It is imperative for integrating traditional Chinese cultural elements with new thoughts of modern graphic design. The purpose of such integration is also to strengthen the position of China's graphic design in the world. I hope that China's graphic design could stand erect in the world for ever with the posture of a winner.

\section{References:}

[1] Feng Yu, Discussion on Influence of Traditional Culture on Contemporary Graphic Design [J], 2014 (01);

[2] Dai Dan, Discussion on Application of Traditional Chinese Culture in Graphic Design [J], Beauty \& Times, 2014 (05);

[3] Shi Tong, Discussion on Application of Traditional Chinese Elements in Graphic Design [J], Yellow River of the Song, 2010 (07);

[4] Shi Di, Integration and Breakthrough of Chinese Elements in Graphic Design [D], Changchun University of Technology, 2010 (02). 